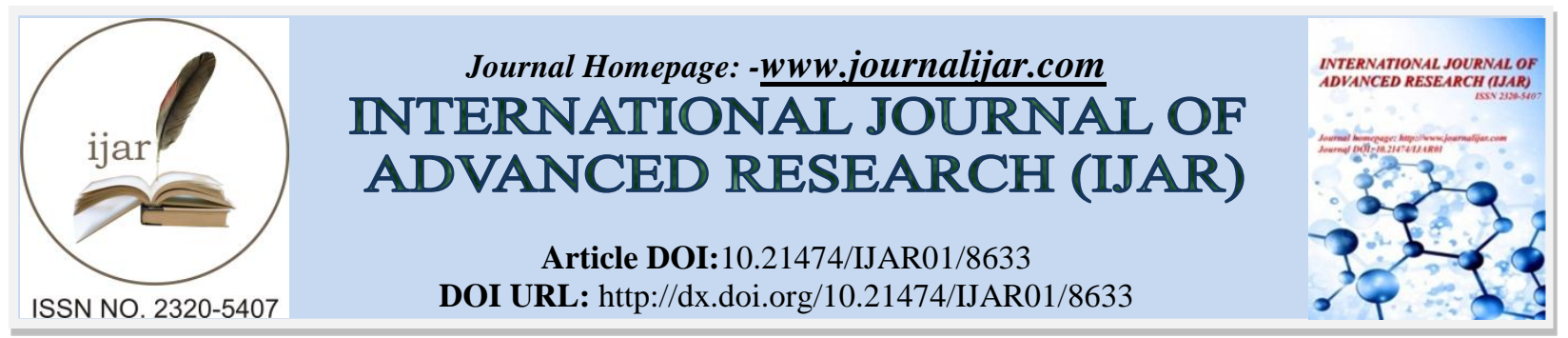

RESEARCH ARTICLE

\title{
A RARE CASE REPORT OF NONSYNDROMIC HYPODONTIA WITH ANKYLOGLOSSIA.
}

\author{
Manisha kaushik ${ }^{1}$, Updesh Masih $^{2}$, Kanupriya Rathore ${ }^{3}$ And Pooja mahay ${ }^{4}$. \\ 1. Post graduate student, Department of peadiatric dentistry,K D dental college and hospital, Mathura. \\ 2. Prof and head,Department of peadiatric dentistry,K D dental college and hospital, Mathura. \\ 3. Reader, Department of peadiatric dentistry,Jodhpur dental college, jodhpur. \\ 4. Reader, Department of oral medicine and radiology,K D dental college and hospital, Mathura.
}

\section{Manuscript Info}

\section{Manuscript History}

Received: 06 January 2018

Final Accepted: 08 February 2019

Published: March 2019

Key words:-

Ankyloglossia, Lingual frenectomy,

Hypodontia.

\section{Abstract}

This case report describes a case where a 14 year old female patient was diagnosed with ankyloglossia and congenitally missing mandibular incisors and canines. The treatment planned was frenectomy and removable partial denture. The patient underwent lingual frenectomy procedure by scalpel method under local anesthesia without any complications. After a follow up the healing was uneventful without scar formation. The tongue showed good healing with protrusion several millimeters beyond the lower lip and aftercare with speech therapy for rehabilitation of the patient.

Copy Right, IJAR, 2019,. All rights reserved.

\section{Introduction:-}

Ankyloglossia, commonly known as tongue-tie, is a congenital anomaly characterized by an abnormally short lingual frenum. The phenotype varies from absence of clinical significance to rare complete ankyloglossia where the ventral part of the tongue is fused to the floor of the mouth (1). Partial ankyloglossia is caused by a frenum of the tongue that is abnormally short or is attached too close to the tip of the tongue. Hypodontia refers to the condition where there is absence of one or a few teeth only (2). Hypodontia, especially in the anterior region of the mouth can seriously affect a child both physically and emotionally.

\section{Case Report}

\section{Case Presentation}

A 14 year old female patient reported to the Department of Pedodontics and Preventive dentistry with the complaint of missing lower front teeth and difficulty in speech and tongue movements. Intraoral clinical examination revealed absence of mandibular incisors and canines, mandibular anterior alveolar ridge was very thin and knife edged and presence of ankyloglossia [Fig. 1] which was classified as Class II by utilizing Kotlow's assessment (3).

\section{Treatment Plan}

The treatment planned was frenectomy and removable partial denture. The surgical procedure was explained and informed consent was obtained. Oral prophylaxis was done and impressions were made for fabrication of removable partial denture as an immediate and temporary treatment to restore the missing teeth and esthetics. After the growth completion, fabrication of fixed partial prosthesis was advocated. After routine hematological investigations lingual frenectomy was undertaken under local anesthesia with 2\% lignocaine and 1: 80000 adrenaline.

Corresponding Author:-Manisha kaushik.

Address:-Post graduate student, Department of peadiatric dentistry,K D dental college and hospital, 


\section{Surgical procedure}

A sling suture was passed through the tip of the tongue to facilitate tongue retraction [Fig. 2] and hemostat was used to clamp the frenum, no. 15 blade was used to make incisions on the either side of the frenum [Fig. 3]. A diamond shaped wound was made and the frenum was removed [Fig. 4]. The blunt end of the instrument was used to relieve the pull by muscle fibers so that tension free closure of the wound edges can be obtained. Tongue movement was checked by protrusion to assess complete elimination of the frenum. 8 interrupted sutures using 3-0 black silk were placed from the tip to the base of the frenum in a line [Fig. 5]. Sling suture was removed from tongue and protrusion of the tongue was checked to assess elimination of frenal tension [Fig. 6]. The patient was given medications for 5 days to reduce post operative pain and infection. Patient was instructed to rinse her mouth with $0.2 \%$ chlorhexidine mouth wash for 1 week and maintain good oral hygiene and stretching exercises were advocated after one day to make sure that the area that was released does not heal back together. Sutures were removed after seven days and the healing was satisfactory. The tongue showed good healing with protrusion beyond lower lip at six months follow up visit (Fig. 7).

\section{Discussion:-}

Ankyloglossia is a Greek term originating from the words agkylos (tied) and glossa (tongue). It is an embryological anatomical malformation that usually affects males more than females in a 3:1 ratio. It occurs in newborns with an incidence of about $5 \%$, more frequently as an isolated event and sometimes associated to malformative syndromes (Simpson-Golabi-Behemel Syndrome, Optiz Syndrome, Beckwitz-Wiedemann Syndrome, Orofacial-digital Syndrome; cleft palate) (4). Tongue movements are responsible for carrying out orofacial functions like sucking, chewing, swallowing, speech and articulation. These movements can be altered due to positioning of the frenum. The problems commonly associated with ankyloglossia are: it can cause functional problems in breast feeding. Breastfeeding difficulty is caused by the lingual hypomobility and the resulting inability of the nursing infant to squeeze the nipple against the upper arch and hard palate during suction (5). Tongue is a fundamental organ for deglutition and a short lingual frenum can cause difficulty in swallowing. The onset of speech is not prevented or delayed, but interferes with speech articulation. A study on 1402 patients reported that more frequent speech disorders were: omission and substitution of $/ \mathrm{r} /$, and consonant clusters with $/ \mathrm{r} /$, and of $/ \mathrm{s} / \mathrm{and} / \mathrm{z} /$. frontal and lateral lisps also occurred (6). It has also been associated with midline diastema (7), can interfere with maxillomandibular growth, results in gingival recession of mandibular central incisors due to frenal pull (8). It can also prevent the tongue from contacting the anterior palate, leading to a retained infantile swallow, resulting in an open bite deformity (9). Restricted tongue's sweeping action on the teeth and spreading of saliva can cause dental caries. Some authors have also claimed that some ankyloglossia cases can be associated with upward and forward displacement of the epiglottis and larynx, resulting in various degrees of dyspnoea (10) The ankyloglossia can be classified into four classes based on Kotlow's assessment (3) (Table 1)

The morpho-functional assessment proposed by Hazelbaker (11) evaluates the degree of ankyloglossia.(Table 2)

Table 1:-Kotlow's classification.

\begin{tabular}{|l|l|}
\hline \multicolumn{1}{|c|}{ Type } & \multicolumn{1}{|c|}{ Movement of the tongue } \\
\hline Clinically acceptable, normal range of free tongue movement & Greater than $16 \mathrm{~mm}$ \\
\hline Class I: Mild ankyloglossia & 12 to $16 \mathrm{~mm}$ \\
\hline Class II: Moderate ankyloglossia & 8 to $11 \mathrm{~mm}$ \\
\hline Class III: Severe ankyloglossia & 3 to $7 \mathrm{~mm}$ \\
\hline Class IV: Complete ankyloglossia & less than $3 \mathrm{~mm}$ \\
\hline
\end{tabular}

Table 2:-Hazelbaker's Assessment tool for appearance and function of the tongue

\begin{tabular}{|l|l|}
\multicolumn{1}{|c|}{ Appearance items } & \multicolumn{1}{|c|}{ Function items } \\
\hline \hline \multicolumn{1}{|c|}{ Appearance of tongue when lifted } & \multicolumn{1}{|c|}{ Lateralization } \\
\hline \hline 2: Round or square & 2: Complete \\
\hline 1: Slight cleft in tip apparent & 1: Body or tongue but no tongue tip \\
\hline 0: Heart or V-shaped & 0: None \\
\hline \hline & \multicolumn{1}{|c|}{ Lift ongue } \\
\hline \hline 2: Very elastic frenulum & 2: Tip to mid-mouth \\
\hline 1: Moderately elastic & 1: Only edges to mid-mouth \\
\hline 0: Little or no elasticity & 0: Tip stays at lower alveolar ridge or rises to mid- \\
\hline
\end{tabular}




\begin{tabular}{|c|c|}
\hline & mouth only with jaw closure \\
\hline Length of lingual frenulum when tongue lifted & $\begin{array}{r}\text { Extension of tongue } \\
\end{array}$ \\
\hline 2: $>1 \mathrm{~cm}$ or embedded in tongue & 2: Tip over lower lip \\
\hline $1: 1 \mathrm{~cm}$ & 1: Tip over lower gum only \\
\hline $0:<1 \mathrm{~cm}$ & $\begin{array}{l}0 \text { : Neither of the above, or anterior or mid-tongue } \\
\text { humps }\end{array}$ \\
\hline Attachment of lingual frenulum to tongue & Spread of anterior tongue \\
\hline 2: Posterior to tip & 2: Complete \\
\hline 1: At tip & 1: Moderate of partial \\
\hline 0: Notched tip & 0: Little or none \\
\hline Attachment of lingual frenulum to inferior alveolar ridge & Cupping of tongue \\
\hline 2: Attached to floor of mouth or well below ridge & 2: Entire edge, firm cup \\
\hline 1: Attached just below ridge & 1: Side edges only, moderate cup \\
\hline 0: Attached at ridge & 0: Poor or no cup \\
\hline & Peristalsis \\
\hline & 2: Complete, anterior or posterior \\
\hline & 1: Partial, originating posterior to tip \\
\hline & $0:$ None or reverse peristalsis \\
\hline & Snap-back \\
\hline & 2: none \\
\hline & 1: periodic \\
\hline & 0: frequent or with each suck \\
\hline \multicolumn{2}{|c|}{$\begin{array}{l}\text { Scoring } \\
14=\text { perfect score (regardless of appearance item score) } \\
11=\text { acceptable if appearance item score is } 10 \\
<11=\text { function impaired; frenotomy should be considered if management fails } \\
\text { Frenotomy is necessary if function score is }<11 \text { and appearance score is }<8\end{array}$} \\
\hline
\end{tabular}

Early diagnosis and intervention in ankyloglossia are fundamental for the subsequent morpho-functional development of the child and of the adolescent. The diagnosis and management of ankyloglossia in infants remains controversial. In some cases the frenulum is reported to tear spontaneously during infancy. It should be stated that a short frenum is not always inelastic or fibrotic and, despite the reduced length, it may allow a normal lingual mobility thus not necessitating a reduction intervention; also, the elasticity of the floor of the mouth can mitigate the effects of the ankyloglossia and help the lingual mobility (12). Feeding difficulties may be a reason to consider early surgery. There are four surgical interventions available - frenotomy, frenectomy, revision of the frenum by laser and/or revision by electrocautery or monopolar diathermy. The conventional technique involves excision of the frenum by using a scalpel. Although the technique described by Hall (13) gives predictable results, it has a few drawbacks compared to laser-assisted frenectomy.

The suturing on the ventral surface can at times lead to blockage of Wharton's duct, causing submandibular swelling, Surgical manipulations in the ventral tongue region may also damage the lingual nerve (14) and result in numbness of the tongue tip, Suturing can also cause contamination by a "wicking effect", causing secondary infection (15). This makes it necessary to prescribe postoperative antibiotics. Electrocautery is an efficacious, economical and safe treatment as operative and postoperative bleeding with electrocautery is significantly less than conventional surgery (16). Laser have an edge over conventional technique. The advantages of laser treatment are: shorter operative working time, tissue cauterization and sterilization, hemostasis, less local anesthesia requirement, and fewer postoperative complications (pain, swelling and infection) and lowered anxiety levels observed during this procedure (17).

Hypodontia refers to the condition where there is absence of one or a few teeth only. Hypodontia, especially in the anterior region of the mouth can seriously affect a child both physically and emotionally. In such cases, the various treatment approaches are orthodontic, combined orthodontic-prosthetic, fixed prosthetic, removable prosthetic or implant retained prosthetic treatment. Interim restorations may be provided before definitive care is given to ease the transition of the child into early adolescence. This includes composite additions, resin retained-bridge veneers, 
onlays and partial dentures which contribute to an improvement in aesthetics and function of the patient (2). Where there are edentulous spans of short length it may be possible to place tooth-supported bridgework, however, conventional bridgework is generally contraindicated in young patients with relatively immature pulps and where abutment teeth are sound. Traditionally, metal alloy has been used as the material for the framework, but fiber reinforced composite is advocated today for their favorable elastic modulus as compared to metals and better adhesion of the composite luting agent to the framework (18). The treatment option for multiple missing teeth are generally limited to removable partial dentures as they replace soft and hard tissue deficiencies without recourse to invasive surgery, but with continued growth will need to be replaced frequently. The large prosthetic constructions should be avoided as it restrains jaw growth and development. Implant therapy is still controversial in children. The placement of implant-supported prosthesis is unlikely to be considered until clinical signs of growth cessation are present (19). This provides maximum potential for implant placement without bone grafting and prevents infraocclusion of the ankylosed implant (1). The literature still does not offer a consensus regarding the ideal time for implant placement. However, the majority of the authors agree that the anterior part of the mandible is the ideal site of implant placement since the transverse growth is stable starting the age of six (20), The use of mini-implants for the prosthetic rehabilitation of growing children has been described by Güler (21).

\section{Conclusion:-}

Early diagnosis and intervention in ankyloglossia are fundamental for the subsequent morpho-functional development of the child and of the adolescent. Pediatric dentists examine children from a very early age, it would be useful to have a protocol to enable the Pediatric Dentist and Pediatrician to conclude which lingual frenum require early revision, which ones should be revised later in childhood and which ones do not require treatment. The functional and esthetic changes caused by Hypodontia require the formulation of treatment plan which take into account growth and development of the dentition along with compliance of the child. Multidisciplinary approach is must for the successful management of ankyloglossia and Hypodontia.

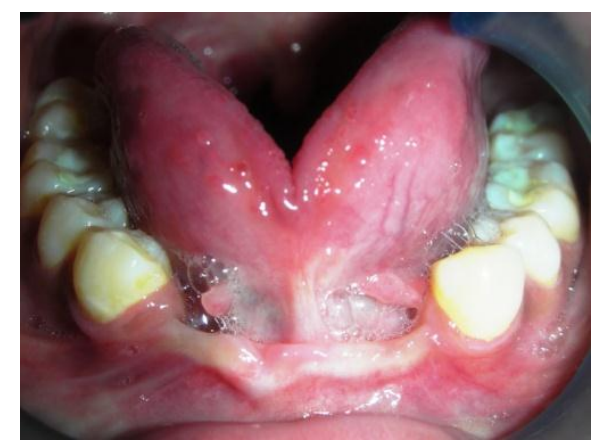

Figure 1: -Preoperative photograph

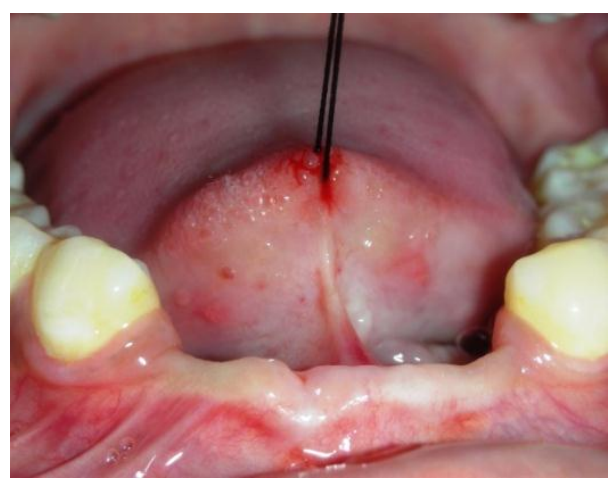

Figure 2:-Sling suture passed through tip of tongue 


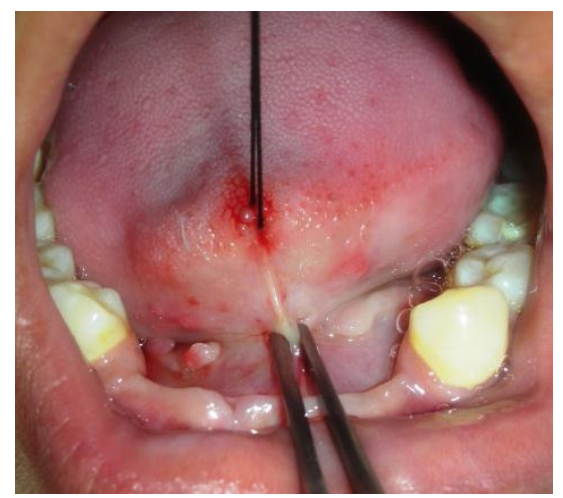

Figure 3:-Hemostat used to clamp the frenum

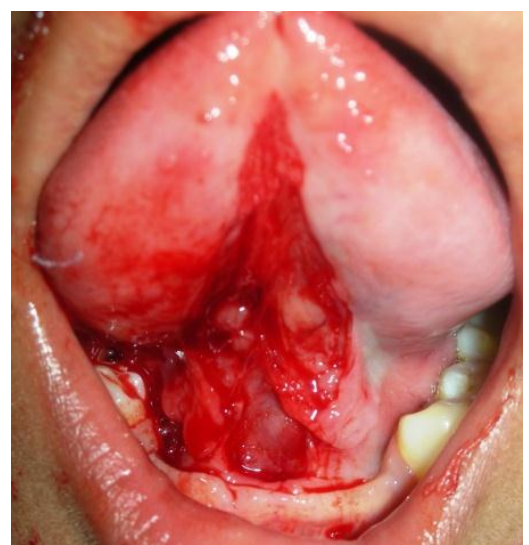

Figure 4:-Postoperative view immediately following first incision

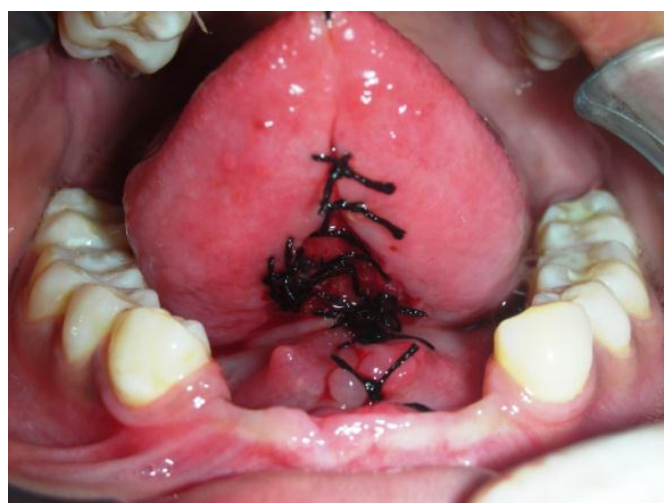

Figure 5:-Following release and division of the frenum, sutures were placed

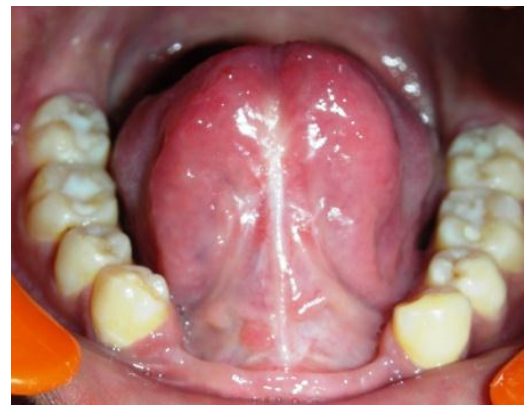

Figure 6:-Postoperative photograph after 7 days 


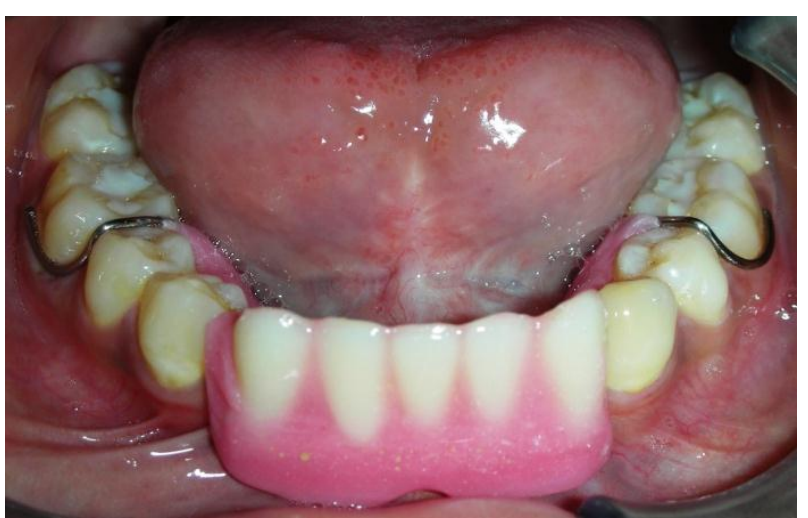

Figure 7:-Postoperative photograph after RPD insertion

\section{References:-}

1. Horton C.E., Crawford H.H., Adamson J.E., Ashbell T.S. Tongue-tie. Cleft Palate J. 1969;6:8-23.

2. Nunn J.H, Carter N.E., Gillgrass T.J., Hobson R.S., Jepson N.J., Meechan J.G., et al. The interdisciplinary management of hypodontia: Background and role of paediatric dentistry. Br Dent J. 2003; 194(5):245-51.

3. Kotlow L.A. Ankyloglossia (tongue-tie): A diagnostic and treatment quandary. Quintessence Int. 1999;30(4):259-62.

4. Klockars T. Familial ankyloglossia (tongue tie). Int J Pediatr Otorhinolaryng. 2007;71:1321-4.

5. Wallace H., Clarke S. Tongue tie division in infants with breast feeding difficulties. Int $\mathbf{J}$ Pediatr Otorhinolaryngol. 2006;70(7):1257-61.

6. Queiroz Marchesan. Lingual frenulum: classification and speech interference. Int J Orofacial Myology.2004;30:31-8.

7. Hasan N. Tongue as a cause of deformity of lower central incisor. J Pediatr Surg. 1973;8: 985.

8. Ewart N.P. A lingual mucogingival problems associated with ankyloglossia: a case report. N Z Dent J.1990;86(383):16-7.

9. Suter V.G, Bornstein M.M. Ankyloglossia: Facts and myths in diagnosis and treatment. J Periodontol 2009;80(8):1204-19.

10. Mukai S., Mukai C., Asaoka K. Congenital ankyloglossia with deviation of the epiglottis and larynx: symptoms and respiratory function in adults. Ann Otol Rhinol Laryngol. 1993;102:620-4.

11. Hazelbaker A.K.The assessment tool for lingual frenulum function (ATLFF): Use in a lactation consultant private practice. 1993, Pasadena, California, Pacific Oaks College.

12. Olivi G., Signore A., Olivi M., Genovese M.D. Lingual Frenectomy: functional evaluation and new therapeutical approach. Eur J Paediatr Dent. 2012;13(2):101-6

13. Hall W. Classification of surgical techniques for increasing attached gingiva and techniques for increasing bound-down mucosa. In: Hall, W. Pure Mucogingival Problems; Etiology, Treatment and Prevention. Chicago: Quintessence;1984.p. 75-94.

14. Yang H.M., Woo Y.J., Won S.Y.,Kim D.H., Hu K.S., Kim H.J. Course and distribution of the lingual nerve in the ventral tongue region: anatomical considerations for frenectomy. J Craniofac Surg. 2009;20:1359-63.

15. Takei H., Carranza F. The periodontal flap. In: Newman M, Takei H, Klokkevold P (eds). Carranza's Clinical Periodontolgy, ed 10. Philadelphia: Saunders; 2009. p. 926-36.

16. Tuli A., Singh A. Monopolar diathermy used for correction of Ankyloglossia. JISPPD. 2010;2(28):130-3.

17. Kara C. Evaluation of patient perception of frenectomy: a comparison of Nd:YAG laser and convention techniques. Photomed Laser Surg.2008;26(2):147-52.

18. Van Heumen C.C., Kreulen C.M., Creugers N.H. Clinical studies of fiber-reinforced resin-bonded fixed partial dentures: A systematic review. Eur J Oral Sci 2009; 117:1-6.

19. Jepson N.J., Nohl F.S., Carter N.E., Gillgrass T.J., Meechan J.G., Hobson R.S., Nunn J.H. The interdisciplinary management of hypodontia: restorative dentistry. Br Dent J. 2003;22;194(6):299-304.

20. Singer S.L., Henry P.J., Liddelow G., Rosenberg I. Long Term Follow Up Of Implant Treatment For Oligodontia in an Actively Growing Individual: A Clinical Report. J prosthet Dent 2012;108:279-85.

21. Güler N., Cildir S., Iseri U., Sandalli N., Dilek O. Hypohidrotic ectodermal dysplasia with bilateral impacted teeth at the coronoid process: a case rehabilitated with mini dental implants. Oral Surg Oral Med Oral Pathol Oral Radiol Endod 2005; 99(5):E34-38. 